\title{
Bradyrhizobium lablabi sp. nov., isolated from effective nodules of Lablab purpureus and Arachis hypogaea
}

\author{
Yue Li Chang, ${ }^{1}$ Jing Yu Wang, ${ }^{1}$ En Tao Wang, ${ }^{2}$ Hong Can Liu, ${ }^{3}$ \\ Xin Hua Sui ${ }^{1}$ and Wen Xin Chen ${ }^{1}$
}

Correspondence

Xin Hua Sui

suixh@cau.edu.cn

\author{
${ }^{1}$ State Key Laboratory for Agro-Biotechnology, Key Laboratory of Agro-Microbial Resource and \\ Application, Ministry of Agriculture, College of Biological Sciences, China Agricultural University, \\ Beijing, 100193, PR China \\ ${ }^{2}$ Departamento de Microbiología, Escuela Nacional de Ciencias Biológicas, \\ Instituto Politécnico Nacional, 11340 México D. F., Mexico \\ ${ }^{3}$ Institute of Microbiology, Chinese Academy of Sciences, Beijing, 100101, PR China
}

Arachis hypogaea L. (peanut or groundnut) is an important legume crop that provides food and edible oil for direct human consumption. It plays a significant part in the economy of many countries in the world (El-Akhal et al., 2008). Most rhizobial isolates nodulating peanut belong to

Abbreviations: BOX-PCR, BOX-repeat-based PCR; IGS, 16S-23S rRNA intergenic spacer; ML, maximum-likelihood; MP, maximumparsimony; $\mathrm{NJ}$, neighbour-joining.

The GenBank/EMBL/DDBJ accession numbers for the 16S rRNA gene sequences are GU433448, GU433456 and GU433471 for B. lablabi sp. nov. strains CCBAU $23086^{\top}$, CCBAU 23160 and CCBAU 61434, respectively. The accession numbers for the partial IGS, atpD, recA, glnll, nifH and nodC gene sequences of the three strains, CCBAU 23086 ${ }^{\top}$, CCBAU 23160 and CCBAU 61434, are as follows: GU433583, GU433599 and GU433589 (IGS); GU433473, GU433482 and GU433495 (atpD); GU433522, GU433530 and GU433544 (recA); GU433498, GU433505 and GU433519 ( $\mathrm{g} / \mathrm{l} / \mathrm{l})$; GU433546, GU433553 and GU433563 (nifH); GU433565, GU433571 and GU433581 (nodC).

Supplementary figures and tables are available with the online version of this paper. the genus Bradyrhizobium, such as Bradyrhizobium japonicum (Chen et al., 2003; El-Akhal et al., 2009; Taurian et al., 2006), although some other effective fast-growing rhizobia have also been described (El-Akhal et al., 2008; Taurian et al., 2006).

Lablab purpureus originated in Africa and has been widely distributed in many tropical and subtropical countries where it has become naturalized. In China, $L$. purpureus is grown as an annual or a short-lived perennial in different regions. In these areas, the seeds and immature pods are used for human consumption while the herbage is used as a green manure (Murphy \& Colucci, 1999). To date, only a few rhizobial strains isolated from $L$. purpureus nodules have been studied and most of these have been identified as members of the genus Bradyrhizobium (Morrison et al., 1986), except for the broad host range strain NGR 234 (Trinick, 1980).

During a study of rhizobia nodulating A. hypogaea and L. purpureus grown in southern China, 73 isolates (of a 
total of 93) were characterized and classified in the genus Bradyrhizobium based on 16S rRNA gene RFLP, 16S-23S rRNA intergenic spacer (IGS) RFLP and sequence analyses of $r r s$, IGS, atpD, recA, nodC and nifH genes (unpublished data). Within these bradyrhizobia, five isolates (Table 1) exhibited distinct characteristics and differed from recognized species of the genus Bradyrhizobium. For 16S rRNA gene RFLP, the gene was amplified with primers P1 and P6 by the PCR protocol of Tan et al. (1997) from DNA extracted from each strain by a routine method (Terefework et al., 2001). The amplified fragments were digested with MspI, HinfI, AluI and HaeIII as specified by the manufacturer. The five strains had identical patterns and were defined as the same rRNA type, which grouped together with Bradyrhizobium jicamae PAC68 ${ }^{\mathrm{T}}$, Bradyrhizobium pachyrhizi PAC48 ${ }^{\mathrm{T}}$ and Bradyrhizobium elkanii USDA $76^{\mathrm{T}}$ (see Supplementary Fig. S1 in IJSEM Online) in the cluster analysis using the DICE coefficient and the UPGMA method.

In IGS-RFLP fingerprints, the DNA fragments were amplified with the primers FGPS1490 and FGPL132 (Laguerre et al., 1996) as described by Kwon et al. (2005). The fragments were digested with MspI, HhaI and HaeIII. As found in the 16S rRNA gene analysis, the five strains shared the same pattern, which showed the highest similarity $(65 \%)$ with $B$. jicamae $\mathrm{PAC}^{\mathrm{T}} 8^{\mathrm{T}}$ and $B$. pachyrhizi PAC48 ${ }^{\mathrm{T}}$ (Supplementary Fig. S2), indicating that the five strains might represent a novel species.

BOX-PCR fingerprinting is a powerful tool to estimate the genomic diversity of bacteria and to identify strains (de Bruijn, 1992; Nick \& Lindstrom, 1994; Nick et al., 1999). In the present study, BOX-PCR was performed to characterize the five strains by using the primer BOXAIR (5' CTACGGCAAGGCGACGCTGACG-3') and the procedure of Versalovic et al. (1994). The amplified products were subjected to electrophoresis in $1.5 \%(\mathrm{w} / \mathrm{v})$ agarose gels stained with ethidium bromide. The electrophoretic patterns were analysed by the Gelcompar II program and a UPGMA dendrogram was constructed. Three BOX-PCR fingerprints were obtained, indicating that the strains were not members of the same clone. The strains formed a cluster at $75 \%$ similarity (see Supplementary Fig. S3), which was greater than the similarities obtained among the three recognized species of the genus Bradyrhizobium.

Currently, 16S rRNA gene sequencing is used as the principal method to define a bacterial genus, but it is not sufficiently sensitive to distinguish between closely related species. Due to this limitation, analysis of the IGS region has become a useful tool for determining relatedness among closely related bacteria, including bradyrhizobial strains (Willems et al., 2001, 2003). In addition to the IGS region, several other phylogenetic markers, such as the atpD, recA and $g \ln I I$ genes, have been proposed for species and genospecies descriptions within the genus Bradyrhizobium (Vinuesa et al., 2005). In accordance with previous studies and the RFLP results in the present study, three strains (CCBAU 23086 ${ }^{\mathrm{T}}$, CCBAU 23160 and CCBAU 61434) representing different BOX types and different host origins were chosen for sequence analyses of the IGS and 16S rRNA, atpD, recA, glnII, nodC and nifH genes, as well as for DNADNA hybridization.

The 16S rRNA gene and IGS region of representative strains were amplified in the same manner as in the RFLP analysis. The atpD, recA and glnII genes were amplified and sequenced by using the method of Vinuesa et al. (2005), with primer sets atpD255F/atpD782R, recA41F/recA640R and glnII12F/glnII689R, respectively. The amplification and sequencing of partial nodC and nifH genes was performed with the primers nodC540/nodC1160 (Sarita et al., 2005) and nifH1F/nifH1R (Laguerre et al., 2001), respectively. All the amplified fragments were directly sequenced as described by Hurek et al. (1997). The sequences were aligned with those of related species of the genus Bradyrhizobium using the CLUSTAL W program in the MEGA 4.0 software package (Kumar et al., 1994, 2008). Aligned sequences were analysed by using MEGA 4.0 software to produce a Jukes-Cantor distance (Jukes \& Cantor, 1969) and to construct an optimal unrooted tree using the neighbour-joining (NJ) (Laguerre et al., 1996; Saitou \& Nei, 1987) method. Bootstrap analysis was based on 1000 replications (Felsenstein, 1985). Maximum-likelihood (ML) trees were constructed as unrooted trees using PhyML 3.0 (Guindon \& Gascuel, 2003). The robustness of the ML topologies was inferred by non-parametric bootstrap tests based on 100 data

Table 1. Strains used in this study and relevant information

\begin{tabular}{|lccc|}
\hline Strain & Host plant & Geographical origin & Reference \\
\hline B. lablabi sp. nov. & & & This study \\
CCBAU $23086^{\mathrm{T}}$ & L. purpureus & Anhui, China & This study \\
CCBAU 23160 & A. hypogaea & Anhui, China & This study \\
CCBAU 61434 & L. purpureus & Sichuan, China & This study \\
CCBAU 61428 & L. purpureus & Sichuan, China & This study \\
CCBAU 61430 & L. purpureus & Sichuan, China & Kuykendall et al., 1992 \\
B. elkanii USDA $76^{\mathrm{T}}$ & Glycine max & USA & Ramírez-Bahena et al., 2009 \\
B. pachyrhizi PAC48 & Costa Rica & Ramírez-Bahena et al., 2009 \\
B. jicamae PAC68 & Pachyrhizus erosus & Honduras & Pachyrhizus erosus \\
\hline
\end{tabular}


pseudoreplicates (Felsenstein, 1985). The nucleotide substitution model was selected by Akaike Information Criterion (AIC), as implemented in Modeltest 3.7 (Posada \& Crandall, 1998).

In the phylogenetic tree based on 16S rRNA gene sequences (Fig. 1), the three strains tested had identical gene sequences and were closely related to $B$. jicamae $\mathrm{PAC} 68^{\mathrm{T}}$, B. pachyrhizi PAC $48^{\mathrm{T}}$ and B. elkanii USDA $76^{\mathrm{T}}$, with $99.48 \%, 99.48 \%$ and $99.22 \%$ similarities, respectively. This result was consistent with the results of 16S rRNA gene RFLP analysis. The topology of the ML tree (Supplementary Fig. S4) was very similar to that of the NJ tree.

In the IGS region sequence analysis, the three representative strains showed identical sequences. The topology of the NJ (Supplementary Fig. S5) and the ML phylogenetic (not shown) trees was the same. The IGS region sequence of strain CCBAU $23086^{\mathrm{T}}$ had $95.25 \%, 86.3 \%$ and $86.6 \%$ similarities with that of $B$. jicamae $\mathrm{PAC} 68^{\mathrm{T}}, B$. pachyrhizi $\mathrm{PAC} 48^{\mathrm{T}}$ and $B$. elkanii USDA $76^{\mathrm{T}}$, respectively. Since Willems et al. (2003) have hypothesized that two bradyrhizobial strains with IGS region sequence similarity $<95.5 \%$ usually belong to separate genospecies, our data suggested that the novel group represented a novel genospecies of the genus Bradyrhizobium.

The results of the phylogenetic analyses of the three housekeeping genes with the NJ and ML methods were similar. The NJ tree constructed using the combined sequences of the three genes is shown in Fig. 2 and the ML tree is available as Supplementary Fig. S6. The strains of the novel group were closely related to B. jicamae $\mathrm{PAC} 68^{\mathrm{T}}$, B. pachyrhizi PAC48 ${ }^{\mathrm{T}}$ and B. elkanii USDA $76^{\mathrm{T}}$, which confirmed the relationships obtained in analyses of the $16 \mathrm{~S}$ rRNA gene. The sequence similarities of the atpD, recA and $g \ln I I$ genes were $98.4-100 \%$ among the three representative strains of the novel group and were $<96.5 \%$ between the novel group and reference strains of related species (see Supplementary Table S1). The small differences between strains CCBAU $23086^{\mathrm{T}}$ and CCBAU 23160 in the atpD gene sequence ( $98.98 \%$ similarity) demonstrated that the strains were not a clone, although both shared the same BOX patterns.

Symbiotic (nif and nod) genes do not offer taxonomic information because they are located in easily interchangeable elements (plasmids or in symbiotic islands), but they are required for the successful establishment of the highly specific symbiosis between rhizobia and legumes. Therefore, comparisons of these symbiotic genes may reveal the host ranges of rhizobia. For this reason, the nifH and nodC genes are commonly analysed for the description of novel rhizobial species. The results of the phylogenetic analysis of these genes in the present study showed that the rhizobia isolated from $L$. purpureus and A. hypogaea had identical nifH and nodC gene sequences, implying that they could have the same host spectrum.

In the nifH gene phylogenetic tree (Supplementary Fig. S7), the closest relatives were strain CCBAU 83335 nodulating Sophora alopecuriodes, RST89 nodulating Retama sphaerocarpa and CCBAU 05065 nodulating Vicia pseudorobus, with $96.5 \%, 96.5 \%$ and $96.3 \%$ sequence similarities, respectively. The nifH sequence similarities between the novel group and B. jicamae $\mathrm{PAC} 68^{\mathrm{T}}, B$. pachyrhizi $\mathrm{PAC} 48^{\mathrm{T}}$ and B. elkanii USDA $76^{\mathrm{T}}$ were $92.2 \%, 88.0 \%$ and $88.5 \%$, respectively. When the nodC genes were considered, the similarities between the novel group and recognized species were $<86 \%$, indicating an independent evolutionary history.

As a standard method for species delineation (Graham et al., 1991; Wayne et al., 1987), DNA-DNA hybridization was performed between a representative strain, CCBAU $23086^{\mathrm{T}}$, and reference strains for the novel group (CCBAU 23160 and CCBAU 61434) and for related species (B. jicamae $\mathrm{PAC}^{\mathrm{T}}{ }^{\mathrm{T}}$, B. pachyrhizi $\mathrm{PAC} 48^{\mathrm{T}}$ and B. elkanii USDA $76^{\mathrm{T}}$ ) using Marmur's method for total DNA isolation (Marmur, 1961) and the renaturation-rate technology described previously by De Ley et al. (1970).

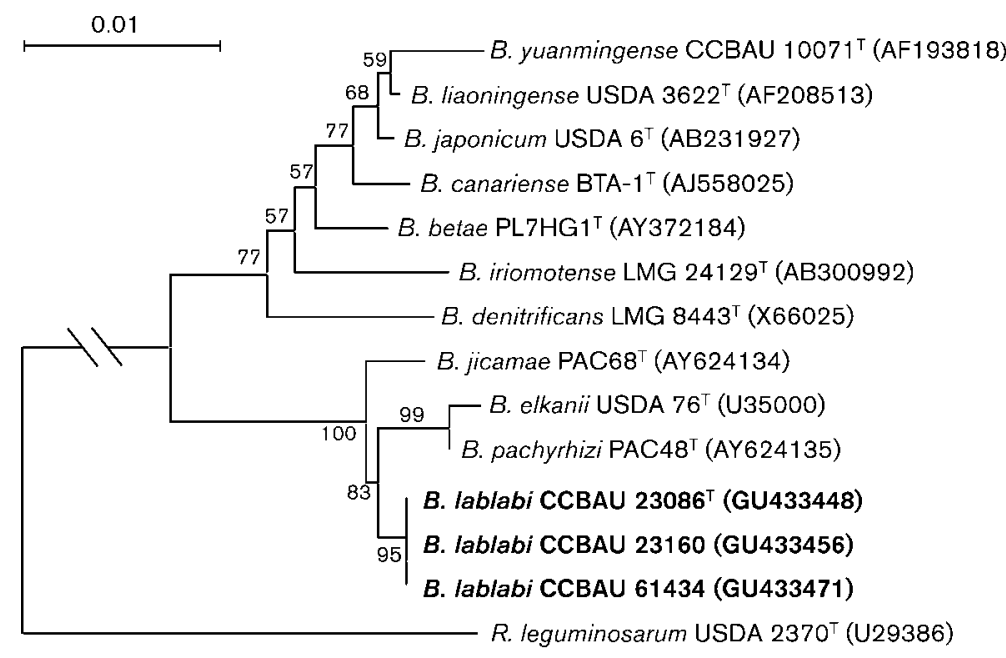
Fig. 1. Neighbour-joining tree reconstructed from 16S rRNA gene sequences showing the phylogenetic relationships of strain CCBAU $23086^{\top}$. Bootstrap values $>50 \%$ are indi- cated at nodes. The sequence of Rhizobium leguminosarum USDA $2370^{\top}$ was used as an outgroup. Bar, $1 \%$ nucleotide substitutions.




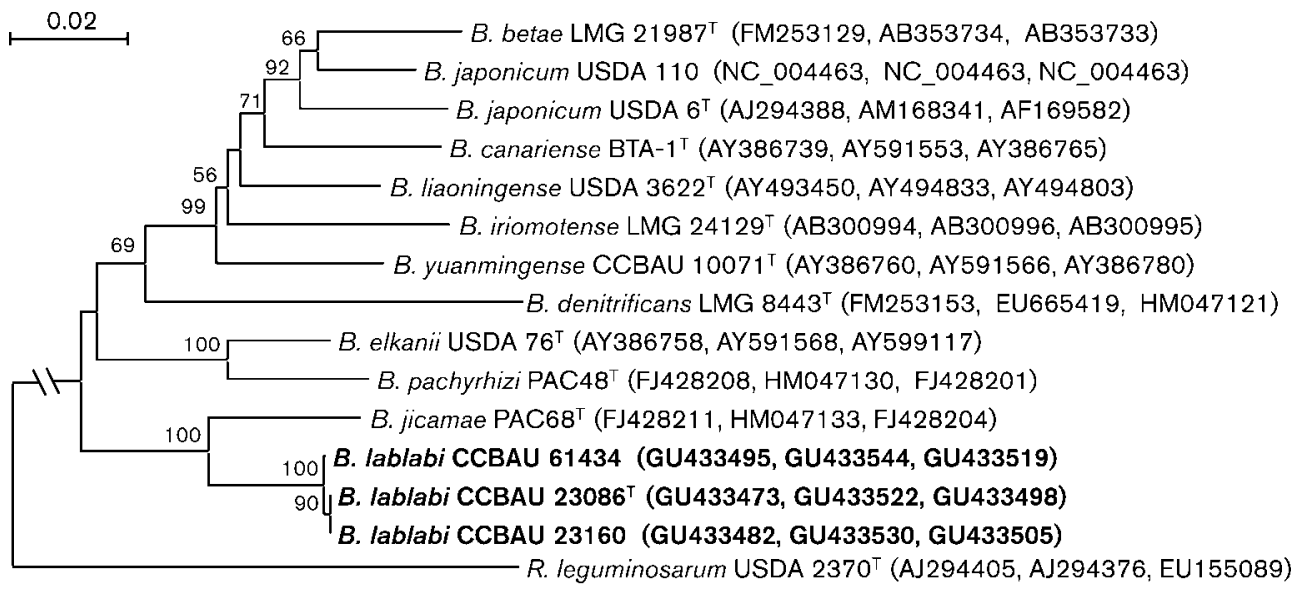

Fig. 2. Neighbour-joining phylogenetic tree based on atp $D, \operatorname{rec} A$ and g/nll gene sequences of Bradyrhizobium lablabi sp. nov. and all ten type strains of the genus Bradyrhizobium. Bootstrap values $>50 \%$ based on 1000 replicates are shown at each node. The GenBank accession numbers for the atp $D, \operatorname{rec} A$ and $g / n / l$ genes are shown in parentheses. Bar, $2 \%$ nucleotide substitutions.

All experiments were performed three times and the mean DNA-DNA relatedness is presented in Supplementary Table S1. The DNA-DNA relatedness of strain CCBAU $23086^{\mathrm{T}}$ with strains CCBAU 23160 and CCBAU 61434 was $100 \%$ and $92.74 \%$ (Supplementary Table S1), respectively. The results of DNA-DNA hybridization between strain CCBAU $23086^{\mathrm{T}}$ and the related type strains $B$. jicamae PAC68 ${ }^{\mathrm{T}}$, B. pachyrhizi PAC $48^{\mathrm{T}}$ and B. elkanii USDA $76^{\mathrm{T}}$ (Supplementary Table S1) indicated that strain CCBAU $23086^{\mathrm{T}}$ showed significantly low relatedness values, in the range of $20.09-31.74 \%$. These values were lower than the threshold value of $70 \%$ DNA-DNA relatedness that is generally accepted as the threshold for the definition of a species (Wayne et al., 1987).

The $\mathrm{G}+\mathrm{C}$ content of the DNA was measured by the thermal denaturation method of De Ley et al. (1970) using Escherichia coli $\mathrm{K}-12$ as a standard. The DNA G $+\mathrm{C}$ content of the three strains was $60.14-62.85 \mathrm{~mol} \%\left(T_{\mathrm{m}}\right)$, which was within the range expected for recognized members of the genus Bradyrhizobium.

To discern and describe the novel genomic species, the cellular fatty acid profile of strain CCBAU $23086^{\mathrm{T}}$ was assayed together with those of $B$. jicamae $\mathrm{PAC}^{\mathrm{T}}{ }^{\mathrm{T}}, B$. pachyrhizi PAC $48^{\mathrm{T}}$ and B. elkanii USDA $76^{\mathrm{T}}$ as reported in other studies (de Lajudie et al., 1998; Quan et al., 2005; Tighe et al., 2000). The strains were grown on YMA medium for 7 days at $28{ }^{\circ} \mathrm{C}$. Fatty acid methyl esters were prepared and separated using a previously described method (Sasser, 1990) and identified with the MIDI Sherlock Microbial Identification System (Sherlock license CD v.6.0), using the TSBA6 database.

A total of 16 fatty acids were detected in strain CCBAU $23086^{\mathrm{T}}$. According to this analysis, the presence of $\mathrm{C}_{16: 1} \omega 9 c$, summed feature 3 and summed feature 7 was common for the novel group and for the type strains of $B$. jicamae, B. pachyrhizi and B. elkanii. The dominant fatty acid for strain CCBAU $23068^{\mathrm{T}}$ was $\mathrm{C}_{18: 1} \omega 7 c$. This was different to the dominant fatty acid found in the three related species, but was consistent with the major fatty acid found for other species of the genus Bradyrhizobium, such as B. japonicum and Bradyrhizobium liaoningense (Islam et al., 2008). Several fatty acids $\left(\mathrm{C}_{12: 0} 2-\mathrm{OH}, \mathrm{C}_{14: 0}\right.$ iso $3-\mathrm{OH}, \mathrm{C}_{15: 1}$ iso $\mathrm{F}$ and $\mathrm{C}_{17: 0} 2-\mathrm{OH}$ ) were found in small amounts only in strain CCBAU $23086^{\mathrm{T}}$ of the novel group. Detailed results are presented in Supplementary Table S2.

The phenotypic features of the three new isolates and the related type strains of species of the genus Bradyrhizobium were determined according to the method described by Gao et al. (1994). Tested features included the utilization of sole carbon and nitrogen sources, resistance to antibiotics, tolerance of $\mathrm{NaCl}$, growth at varying $\mathrm{pH}$ values and the temperature range for growth (Gao et al., 1994). Biochemical tests including the activities of catalase, urease, oxidase and nitrate reductase and reduction of litmus milk, Nile blue and methylene blue were performed according to Smibert \& Krieg (1994). The three strains of the novel species tested in this study had the same characteristics in most cases except that strain CCBAU $23086^{\mathrm{T}}$ could not utilize sodium acetate as a sole carbon source and was resistant to tetracycline hydrochloride $\left(150 \mu \mathrm{g} \mathrm{ml}^{-1}\right)$. Strains CCBAU $23086^{\mathrm{T}}$, CCBAU 23160 and CCBAU 61434 were further compared with the type strains of their closest relatives, B. jicamae $\mathrm{PAC} 68^{\mathrm{T}}$, B. pachyrhizi PAC48 $8^{\mathrm{T}}$ (Ramírez-Bahena et al., 2009) and B. elkanii USDA $76^{\mathrm{T}}$. Distinctive features of the novel group of strains are shown in Table 2 and more features are presented in the description of the novel species.

Nodulation and nitrogen-fixation abilities are important characteristics of the genus Bradyrhizobium and the 
Table 2. Distinctive features of $B$. lablabi sp. nov. and its closest relatives

Strains: 1, B. lablabi sp. nov. CCBAU 23086 ${ }^{\mathrm{T}}$; 2, B. lablabi sp. nov. CCBAU 23160; 3, B. lablabi sp. nov. CCBAU 61434; 4, B. jicamae PAC68 ${ }^{\mathrm{T}}$; 5, B. elkani USDA $76^{\mathrm{T}} ; 6$, B. pachyrhizi PAC48 ${ }^{\mathrm{T}}$. +, Growth or resistant; -, no growth or sensitive; w, weak; ND, not determined. Data were obtained in this study unless indicated.

\begin{tabular}{|c|c|c|c|c|c|c|}
\hline Characteristic & 1 & 2 & 3 & 4 & 5 & 6 \\
\hline Generation time $(\mathrm{h})$ in YM broth & $10-12$ & $10-12$ & $10-12$ & $6-7^{\star}$ & $7-8^{*}$ & $>6^{*}$ \\
\hline \multicolumn{7}{|l|}{ Utilization of sole carbon sources: } \\
\hline Adipic acid & - & - & - & $-\dagger$ & - & + \\
\hline D-Glucose & $\mathrm{w}$ & $\mathrm{w}$ & $\mathrm{w}$ & + & + & + \\
\hline Inulin & + & + & + & + & - & - \\
\hline Maltose & + & + & + & - & + & + \\
\hline Melezitose & - & - & - & + & - & - \\
\hline Salicin & $\mathrm{w}$ & $\mathrm{W}$ & $\mathrm{w}$ & $\mathrm{W}$ & - & - \\
\hline Sodium pyruvate & + & + & + & - & + & + \\
\hline L-Rhamnose & $\mathrm{w}$ & $\mathrm{W}$ & $\mathrm{W}$ & - & - & + \\
\hline Sodium acetate & - & + & + & + & + & + \\
\hline Sodium citrate & + & + & + & - & + & - \\
\hline Sodium formate & - & - & - & - & + & + \\
\hline L-Threonine & + & + & + & - & + & + \\
\hline \multicolumn{7}{|l|}{ Utilization of sole nitrogen sources: } \\
\hline D-Glutamic acid & + & + & + & - & + & + \\
\hline L-Threonine & - & - & - & - & + & + \\
\hline L-Cystine & - & - & - & - & + & + \\
\hline \multicolumn{7}{|l|}{ Resistance to $\left(\mu \mathrm{g} \mathrm{ml}^{-1}\right)$} \\
\hline Ampicillin (50) & + & + & + & - & + & + \\
\hline Streptomycin sulfate (5) & + & + & + & - & + & + \\
\hline Tetracycline $\mathrm{HCl}(150)$ & + & - & - & - & + & + \\
\hline Erythromycin (5) & + & + & + & - & + & + \\
\hline Erythromycin (50) & - & - & - & - & + & + \\
\hline Gentamicin sulfate (5) & + & + & + & $+\dagger$ & + & + \\
\hline Chloramphenicol (50) & + & + & + & - & + & + \\
\hline \multicolumn{7}{|l|}{ Growth in/at: } \\
\hline $1 \%(\mathrm{w} / \mathrm{v}) \mathrm{NaCl}$ & - & - & - & + & + & - \\
\hline $\mathrm{pH} 5.0$ & $\mathrm{w}$ & $\mathrm{W}$ & $\mathrm{w}$ & - & + & + \\
\hline pH 10.0 & + & + & + & - & - & - \\
\hline $37{ }^{\circ} \mathrm{C}$ & + & + & + & - & + & $+\dagger$ \\
\hline
\end{tabular}

${ }^{*}$ Data from Ramírez-Bahena et al. (2009).

$\dagger$ The data from this study were not consistent with those reported previously.

host range is an important feature for the description of novel rhizobial species (Graham et al., 1991). In the present study, cross nodulation tests performed in vermiculite moistened with $\mathrm{N}$-free solution (Vincent, 1970 ) indicated that strains CCBAU $23086^{\mathrm{T}}$, CCBAU 23160 and CCBAU 61434 could nodulate L. purpureus, A. hypogaea and Vigna unguiculata, but not Glycine max, Trifolium repens, Lotus corniculatus, Vigna radiata, Pisum sativum or Medicago sativa under laboratory conditions.

According to all the results obtained in this study, it is concluded that the five new strains represent a novel species in the genus Bradyrhizobium. The name Bradyrhizobium lablabi sp. nov. is proposed for this taxon with strain CCBAU $23086^{\mathrm{T}}$ designated as the type strain.

\section{Description of Bradyrhizobium lablabi sp. nov.}

Bradyrhizobium lablabi (lab'la.bi. N.L. gen. n. lablabi of Lablab referring to the fact that the bacterium was isolated from a root nodule of Lablab purpureus).

Cells are Gram-negative, aerobic, non-spore-forming rods. Colonies on YMA medium are circular, convex and translucent and have a diameter of $1 \mathrm{~mm}$ after incubation for 7-10 days at $28{ }^{\circ} \mathrm{C}$. The generation time is $10-12 \mathrm{~h}$ in $\mathrm{YM}$ broth. The $\mathrm{pH}$ range for growth is $5-10$, with optimum growth at $\mathrm{pH} 7.0$. Growth occurs between $10{ }^{\circ} \mathrm{C}$ and $37^{\circ} \mathrm{C}$, with optimum growth at $28{ }^{\circ} \mathrm{C}$. Does not grow in the presence of $1 \%(\mathrm{w} / \mathrm{v}) \mathrm{NaCl}$. In addition to the carbon sources listed in Table 2, the type strain is also able to utilize D-galactose, sodium DL-malate, D-ribose, sodium D-gluconate, D-arabinose, hippuric acid, sodium succinate, 
D-sorbitol, sorbose, soluble starch, tartaric acid, D-xylose, L-proline and calcium gluconate as sole carbon sources. Does not utilize adipic acid, D-amygdalin, lactose, Dmannose, L-methionine, melibiose, raffinose, sucrose, syringic acid, L-arginine, DL-asparagine, glycine, L-glycine, dextrin or dulcitol as a sole carbon source. Is able to grow on DL-alanine, L-arginine, hypoxanthine, L-isoleucine, Lphenylalanine, L-valine, $\mathrm{L}$-aspartic acid and L-lysine as sole nitrogen sources. No growth with glycine, L-glutamic acid or L-methionine as sole nitrogen sources. The type strain is resistant to $\left(\mu \mathrm{g} \mathrm{ml}^{-1}\right)$, chloramphenicol (5), kanamycin (5), neomycin sulfate (5), tetracycline hydrochloride (150) and gentamicin (5). Detailed distinctive features and the fatty acid content are shown in Table 2 and Supplementary Table S2. Strains can be distinguished by their housekeeping gene sequences and by DNA-DNA hybridization (Supplementary Table S1).

The type strain, CCBAU $23086^{\mathrm{T}}\left(=\mathrm{LMG} 25572^{\mathrm{T}}=\mathrm{HAMBI}\right.$ $\left.3052^{\mathrm{T}}\right)$, was isolated from effective nodules of $L$. purpureus in Anhui province, China. The DNA G $+\mathrm{C}$ content of the type strain is $60.14 \mathrm{~mol} \%$. Additional strains are CCBAU 23160 and CCBAU 61434.

\section{Acknowledgements}

We thank Dr Encarna Velázquez (Departamento de MicroBiología y Genética, Universidad de Salamanca, Spain) for supplying the B. jicamae $\mathrm{PAC}^{\mathrm{T}}{ }^{\mathrm{T}}$ and B. pachyrhizi PAC48 ${ }^{\mathrm{T}}$. This work was supported by the Foundation of the State Key Basic Research and Development Plan of China (grant 2010CB126500), by National Natural Science Foundation of China (project no. 30970004) and by the National Project for Basic S\&T Platform Construction (grant 2005DKA21201-10).

\section{References}

Chen, Q., Zhang, X., Terefework, Z., Kaijalainen, S., Li, D. \& Lindström, K. (2003). Diversity and compatibility of peanut (Arachis hypogaea L.) bradyrhizobia and their host plants. Plant Soil 255, 605-617.

de Bruijn, F. J. (1992). Use of repetitive (repetitive extragenic palindromic and enterobacterial repetitive intergeneric consensus) sequences and the polymerase chain reaction to fingerprint the genomes of Rhizobium meliloti isolates and other soil bacteria. Appl Environ Microbiol 58, 2180-2187.

de Lajudie, P., Willems, A., Nick, G., Moreira, F., Molouba, F., Hoste, B., Torck, U., Neyra, M., Collins, M. D. \& other authors (1998). Characterization of tropical tree rhizobia and description of Mesorhizobium plurifarium sp. nov. Int J Syst Bacteriol 48, 369-382.

De Ley, J., Cattoir, H. \& Reynaerts, A. (1970). The quantitative measurement of DNA hybridization from renaturation rates. Eur $J$ Biochem 12, 133-142.

El-Akhal, M., Rincon, A., Arenal, F., Lucas, M., El Mourabit, N., Barrijal, S. \& Pueyo, J. (2008). Genetic diversity and symbiotic efficiency of rhizobial isolates obtained from nodules of Arachis hypogaea in northwestern Morocco. Soil Biol Biochem 40, 2911-2914.

El-Akhal, M. R., Rincon, A., Mourabit, N. E., Pueyo, J. J. \& Barrijal, S. (2009). Phenotypic and genotypic characterizations of rhizobia isolated from root nodules of peanut (Arachis hypogaea L.) grown in Moroccan soils. J Basic Microbiol 49, 415-425.
Felsenstein, J. (1985). Confidence limits on phylogenies: an approach using the bootstrap. Evolution 39, 783-791.

Gao, J., Sun, J., Li, Y., Wang, E. \& Chen, W. (1994). Numerical taxonomy and DNA relatedness of tropical rhizobia isolated from Hainan Province, China. Int J Syst Bacteriol 44, 151-158.

Graham, P., Sadowsky, M., Keyser, H., Barnet, Y., Bradley, R., Cooper, J., De Ley, D., Jarvis, B., Roslycky, E. \& other authors (1991). Proposed minimal standards for the description of new genera and species of root-and stem-nodulating bacteria. Int J Syst Evol Microbiol 41, 582-587.

Guindon, S. \& Gascuel, O. (2003). A simple, fast, and accurate algorithm to estimate large phylogenies by maximum likelihood. Syst Biol 52, 696-704.

Hurek, T., Wagner, B. \& Reinhold-Hurek, B. (1997). Identification of $\mathrm{N}_{2}$-fixing plant- and fungus-associated Azoarcus species by PCRbased genomic fingerprints. Appl Environ Microbiol 63, 4331-4339.

Islam, M. S., Kawasaki, H., Muramatsu, Y., Nakagawa, Y. \& Seki, T. (2008). Bradyrhizobium iriomotense sp. nov., isolated from a tumorlike root of the legume Entada koshunensis from Iriomote Island in Japan. Biosci Biotechnol Biochem 72, 1416-1429.

Jukes, T. H. \& Cantor, C. R. (1969). Evolution of protein molecules. In Mammalian Protein Metabolism, vol. 3, pp. 21-132. Edited by H. N. Munro. New York: Academic Press.

Kumar, S., Tamura, K. \& Nei, M. (1994). MEGA: Molecular evolutionary genetics analysis software for microcomputers. Comput Appl Biosci 10, 189-191.

Kumar, S., Nei, M., Dudley, J. \& Tamura, K. (2008). MEGA: A biologistcentric software for evolutionary analysis of DNA and protein sequences. Brief Bioinform 9, 299-306.

Kuykendall, L. D., Saxena, B., Devine, T. E. \& Udell, S. E. (1992). Genetic diversity in Bradyrhizobium japonicum Jordan 1982 and a proposal for Bradyrhizobium elkanii sp. nov. Can J Microbiol 38, 501505.

Kwon, S. W., Park, J. Y., Kim, J. S., Kang, J. W., Cho, Y. H., Lim, C. K., Parker, M. A. \& Lee, G. B. (2005). Phylogenetic analysis of the genera Bradyrhizobium, Mesorhizobium, Rhizobium and Sinorhizobium on the basis of $16 \mathrm{~S}$ rRNA gene and internally transcribed spacer region sequences. Int J Syst Evol Microbiol 55, 263-270.

Laguerre, G., Mavingui, P., Allard, M. R., Charnay, M. P., Louvrier, P., Mazurier, S. I., Rigottier-Gois, L. \& Amarger, N. (1996). Typing of rhizobia by PCR DNA fingerprinting and PCR-restriction fragment length polymorphism analysis of chromosomal and symbiotic gene regions: application to Rhizobium leguminosarum and its different biovars. Appl Environ Microbiol 62, 2029-2036.

Laguerre, G., Nour, S. M., Macheret, V., Sanjuan, J., Drouin, P. \& Amarger, N. (2001). Classification of rhizobia based on nodC and nifH gene analysis reveals a close phylogenetic relationship among Phaseolus vulgaris symbionts. Microbiology 147, 981-993.

Marmur, J. (1961). A procedure for the isolation of deoxyribonucleic acid from microorganisms. J Mol Biol 3, 208-218.

Morrison, N., Trinick, M. \& Rolfe, B. (1986). Comparison of the host range of fast-growing $R$. japonicum strains with a fast-growing isolates from Lablab. Plant Soil 92, 313-317.

Murphy, A. \& Colucci, P. (1999). A tropical forage solution to poor quality ruminant diets: A review of Lablab purpureus. Livestock Res Rural Dev 11. http://www.lrrd.org/lrrd11/2/colu112.htm

Nick, G. \& Lindstrom, K. (1994). Use of repetitive sequences and the polymerase chain reaction to fingerprint the genomic DNA of Rhizobium galegae strains and to identify the DNA obtained by sonicating the liquid cultures and root nodules. Syst Appl Microbiol 17, 265-273. 
Nick, G., de Lajudie, P., Eardly, B. D., Suomalainen, S., Paulin, L., Zhang, X., Gillis, M. \& Lindström, K. (1999). Sinorhizobium arboris sp. nov. and Sinorhizobium kostiense sp. nov., isolated from leguminous trees in Sudan and Kenya. Int J Syst Bacteriol 49, 1359-1368.

Posada, D. \& Crandall, K. A. (1998). MODELTEST: testing the model of DNA substitution. Bioinformatics 14, 817-818.

Quan, Z. X., Bae, H. S., Baek, J. H., Chen, W. F., Im, W. T. \& Lee, S. T. (2005). Rhizobium daejeonense sp. nov. isolated from a cyanide treatment bioreactor. Int J Syst Evol Microbiol 55, 2543-2549.

Ramírez-Bahena, M. H., Peix, A., Rivas, R., Camacho, M., RodríguezNavarro, D. N., Mateos, P. F., Martínez-Molina, E., Willems, A. \& Velázquez, E. (2009). Bradyrhizobium pachyrhizi sp. nov. and Bradyrhizobium jicamae sp. nov., isolated from effective nodules of Pachyrhizus erosus. Int J Syst Evol Microbiol 59, 1929-1934.

Saitou, N. \& Nei, M. (1987). The neighbor-joining method: a new method for reconstructing phylogenetic trees. Mol Biol Evol 4, 406-425.

Sarita, S., Sharma, P. K., Priefer, U. B. \& Prell, J. (2005). Direct amplification of rhizobial nodC sequences from soil total DNA and comparison to nodC diversity of root nodule isolates. FEMS Microbiol Ecol 54, 1-11.

Sasser, M. (1990). Identification of Bacteria by Gas Chromatography of Cellular Fatty Acids. Technical Note 101. Newark, DE: Microbial MIDI Inc.

Smibert, R. M. \& Krieg, N. R. (1994). Phenotypic characterization. In Methods for General and Molecular Bacteriology, pp. 607-654. Edited by P. Gerhardt, R. G. E. Murray, W. A. Wood \& N. R. Krieg. Washington, DC: American Society for Microbiology.

Tan, Z. Y., Xu, X. D., Wang, E. T., Gao, J. L., Martinez-Romero, E. \& Chen, W. X. (1997). Phylogenetic and genetic relationships of Mesorhizobium tianshanense and related rhizobia. Int J Syst Bacteriol 47, 874-879.

Taurian, T., Ibanez, F., Fabra, A. \& Aguilar, O. (2006). Genetic diversity of rhizobia nodulating Arachis hypogaea L. in central Argentinean soils. Plant Soil 282, 41-52.

Terefework, Z., Kaijalainen, S. \& Lindström, K. (2001). AFLP fingerprinting as a tool to study the genetic diversity of Rhizobium galegae isolated from Galega orientalis and Galega officinalis. J Biotechnol 91, 169-180.

Tighe, S. W., de Lajudie, P., Dipietro, K., Lindström, K., Nick, G. \& Jarvis, B. D. W. (2000). Analysis of cellular fatty acids and phenotypic relationships of Agrobacterium, Bradyrhizobium, Mesorhizobium, Rhizobium and Sinorhizobium species using the Sherlock Microbial Identification System. Int J Syst Evol Microbiol 50, 787-801.

Trinick, M. (1980). Relationships amongst the fast-growing rhizobia of Lablab purpureus, Leucaena leucocephala, Mimosa spp., Acacia farnesiana and Sesbania grandiflora and their affinities with other rhizobial groups. J Appl Microbiol 49, 39-53.

Versalovic, J., Schneider, M., de Bruijn, F. J. \& Lupski, J. R. (1994). Genomic fingerprinting of bacteria using repetitive sequence based PCR (rep-PCR). Methods Mol Cell Biol 5, 25-40.

Vincent, J. M. (1970). The cultivation, isolation and maintenance of rhizobia. In A Manual for the Practical Study of the Root-Nodule Bacteria, pp. 1-13. Edited by J. M. Vincent. Oxford: Blackwell Scientific.

Vinuesa, P., Silva, C., Werner, D. \& Martínez-Romero, E. (2005). Population genetics and phylogenetic inference in bacterial molecular systematics: the roles of migration and recombination in Bradyrhizobium species cohesion and delineation. Mol Phylogenet Evol 34, 29-54.

Wayne, L., Brenner, D., Colwell, R., Grimont, P. A. D., Kandler, O., Krichevsky, M. I., Moore, L. H., Moore, W. E. C., Murray, R. G. E. \& other authors (1987). Report of the ad hoc committee on reconciliation of approaches to bacterial systematics. Int J Syst Bacteriol 37, 463-464.

Willems, A., Coopman, R. \& Gillis, M. (2001). Comparison of sequence analysis of 16S-23S rDNA spacer regions, AFLP analysis and DNA-DNA hybridizations in Bradyrhizobium. Int J Syst Evol Microbiol 51, 623-632.

Willems, A., Munive, A., de Lajudie, P. \& Gillis, M. (2003). In most Bradyrhizobium groups sequence comparison of 16S-23S rDNA internal transcribed spacer regions corroborates DNA-DNA hybridizations. Syst Appl Microbiol 26, 203-210. 